\title{
Prevalence of HCV Infection in Newly-Diagnosed HIV Patients in the City of Belém, Pará, Brazil: A Preliminary Report
}

\author{
Márcio Nahum Lobo ${ }^{1}$, Jessica Leticia Santos Barata ${ }^{2}$, Ronald Ferreira de Jesus ${ }^{2}$, \\ Julimar Benedita Gomes de Oliveira ${ }^{2}$, Pedro Leão Fontes Neto ${ }^{1}$, \\ Andre Luis Ribeiro Ribeiro ${ }^{3}$ and Luiz Fernando Almeida Machado ${ }^{1,2,4^{*}}$
}

${ }^{\text {I} B i o l o g y}$ of Infectious and Parasitic Agents Post-Graduate Program, Federal University of Pará, Belém, Pará, Brazil

${ }^{2}$ Microbiology Specialization, Institute of Biological Sciences, Federal University of Pará, Belém, Pará, Brazil

${ }^{3}$ Clinical Lecturer, Department of Oral and Maxillofacial Surgery, School of Dentistry, University Centre of Para - CESUPA, Belem, Pará, Brazil

${ }^{4}$ Virology Laboratory, Institute of Biological Sciences, Federal University of Pará, Belem, Pará, Brazil

*Corresponding author

\section{A B S T R A C T}

\begin{tabular}{|c|}
\hline $\begin{array}{l}\text { Ke e y w o r d s } \\
\text { HIV, HCV, Coinfection, } \\
\text { Seroepidemiology }\end{array}$ \\
\hline Article Info \\
\hline $\begin{array}{l}\text { Accepted: } \\
\text { 24 October } 2018 \\
\text { Available Online: } \\
\text { 10 December } 2018\end{array}$ \\
\hline
\end{tabular}

\section{Introduction}

It is estimated that around $3.0 \%$ of the world's population (170 million people) is infected with the hepatitis $\mathrm{C}$ virus (HCV) and about 36.7 million people are living with human immunodeficiency virus (HIV) infection (Low et al., 2016). Co-infection between HCV and HIV has been reported since they share the same infection routes, such as injecting drug
Little is known about the prevalence of immunodeficiency virus (HIV) and hepatitis C virus (HCV) co-infection in the North region of Brazil. This study aimed to describe the seroprevalence of HCV infection in newly-diagnosed patients with HIV in Belém, Pará. A cross-sectional study was conducted between May 2016 and June 2017, which enrolled 185 individuals. Data collection involved the use of a questionnaire and the collection of blood sample for anti-HCV screening. Results indicated only a single individual who was seropositive for both $\mathrm{HIV} / \mathrm{HCV}$ infection, which is considered a very low prevalence $(0.5 \%)$ when compared to other Brazilian regions. 
Northeast region to $2.1 \%$ in the North region (Monteiro et al., 2004). Only a few studies were conducted to analyse the prevalence of HIV/HCV co-infection in the Brazilian Amazon region and limited information is available. This study aimed to investigate the seroprevalence of $\mathrm{HCV}$ infection in individuals newly diagnosed with HIV infection in the city of Belém, state of Pará, Brazil.

\section{Materials and Methods}

A cross-sectional study was carried out between May 2016 and June 2017 in individuals newly diagnosed with HIV infection who spontaneously sought for health assistance in the Centre for Health Care in Acquired Infectious Diseases (CASA DIA), which is a specialized public health service that provide treatment for HIV/AIDS patients in the city of Belém, Pará, Brazil.

Socio-demographic and epidemiological information, such as age, gender, marital status and self-reported risk behaviours (injection drug use, recurrent blood transfusion, multiple sexual partners) were obtained through a semi-structured questionnaire that was applied at the first blood test for $\mathrm{CD}^{+} / \mathrm{CD}^{+} \mathrm{T}$ cell count and plasmatic viral load and before initiating any type of antiretroviral therapy.

All individuals who were older than 18 at collection time, were living in the city of Belém as their fixed residence at least for the past five years, were diagnosed with HIV infection for less than three months and agreed to participate in this study by signing the informed consent form were included in this study. Individuals who refused to sign the consent form or did not meet the above described inclusion criteria were excluded of the study. This study was approved by the Human Research Ethics Committee of the
Health Sciences Institute of the Federal University of Pará under the protocol number 83450318.7.0000.0018.

Five $\mathrm{mL}$ of peripheral venous blood sample was collected by a vacuum collection system in a tube containing EDTA. Anti-HCV antibodies were detected by rapid immunochromatographic test (SD BIOLINE $\mathrm{HCV}$, Alere SA, Giheung-Ku, Republic of Korea) using in accordance to the manufacturer's protocol.

Positive samples were double-checked by ELISA (Ortho Clinical Diagnostics Inc, New Jersey, USA) at the Laboratory of Virology, Institute of Biological Sciences, Federal University of Pará.

\section{Results and Discussion}

Enrolment resulted in a total of 185 participants in this study, $47(25.5 \%)$ were female and $138(74.5 \%)$ male. The mean age was 36.4 years, being the age group between 18 to 30 years $(53.5 \%)$ the most prevalent. Most participants were single (76.2\%) and had complete high school $(57.3 \%)$ as the highest academic degree. Heterosexual orientation (51.4\%), no history of: injecting drug use (90.8\%); blood transfusions (97.9\%); and sexually transmitted infections $(60 \%)$ were the most prevalent demographic data (Table 1).

There was a single individual who presented HCV co-infection ( 1 out of $185,0.5 \%$ ). This participant was a 68-years-old male, had a college degree and reported that he was not a user of injectable drugs and had no history of blood transfusion.

To our knowledge, this is the second study in the State of Pará to describe the seroprevalence of $\mathrm{HCV}$ infection in individuals who were newly diagnosed with HIV in the city of Belém, the state capital. 
Table.1 Epidemiological profile of people newly-diagnosed with HIV/AIDS between May 2016 and June 2017 and older than 18 in the city of Belém, Pará, Brazil

\begin{tabular}{|c|c|c|}
\hline Characteristics & $\mathbf{n}$ & $\%$ \\
\hline \multicolumn{3}{|l|}{ Gender } \\
\hline Male & 138 & 74.5 \\
\hline Female & 47 & 255 \\
\hline \multicolumn{3}{|l|}{ Age range (years) } \\
\hline $18-30$ & 99 & 53.5 \\
\hline $31-40$ & 45 & 24.3 \\
\hline$>40$ & 41 & 22.2 \\
\hline \multicolumn{3}{|l|}{ Marital status } \\
\hline Single & 141 & 76.2 \\
\hline Married & 40 & 21.6 \\
\hline Divorced/Widow(er) & 4 & 2.2 \\
\hline \multicolumn{3}{|l|}{ Educational background } \\
\hline Elementary school & 38 & 20.5 \\
\hline Middle/high school & 106 & 57.3 \\
\hline College & 37 & 20 \\
\hline No answers & 4 & 2.2 \\
\hline \multicolumn{3}{|l|}{ Sexual orientation } \\
\hline Homosexual & 60 & 32.4 \\
\hline Heterosexual & 95 & 51.4 \\
\hline Bisexual & 30 & 16.2 \\
\hline \multicolumn{3}{|l|}{ Injecting drug use } \\
\hline Yes & 1 & 0.6 \\
\hline No & 168 & 90.8 \\
\hline No answer & 16 & 8.6 \\
\hline \multicolumn{3}{|l|}{ Blood transfusion } \\
\hline Yes & 4 & 2.1 \\
\hline No & 181 & 97.9 \\
\hline \multicolumn{3}{|c|}{ Other sexually transmitted disease } \\
\hline Yes & 74 & 40 \\
\hline No & 111 & 60 \\
\hline
\end{tabular}


In Brazil, HIV/HCV coinfection rates vary according to different geographical regions, with the highest rates seen in South and Southeast regions, probably because of higher prevalence of injecting drug use (Brasil, 2002; Pereira et al., 2013).

Surprisingly, the prevalence of anti-HCV found here was 32 times lower $0.5 \%$ than the first study carried out between 1999 and 2000, which reported a prevalence of HCV/HIV coinfection of $16 \%$ (Monteiro et al., 2004) and counted with 406 participants.

In Manaus, the capital city of the Amazonas state, which in combination with the city of Belém are considered the two most important cities in the Brazilian North region that share many sociocultural and demographic characteristics, the reported prevalence was almost 9 times higher (4.4\%) than what was observed in the current study (Victoria et al., 2010).

Our results revealed that the epidemiological profile of newly-diagnosed people with HIV/AIDS in Belém are predominantly young adults male (age between 18 and 30), single, attended the middle/high school, were selfdeclared heterosexual and non-injecting drug users. It suggests that HIV-1 epidemia in Belém is affecting younger individuals when compared to the data of 2003 and also when compared to other states of Brazil, such as Amazonas (Victoria et al., 2010) and Paraná (Tizzot et al., 2016)

No association was found between seropositivity for $\mathrm{HCV}$ and some already known risk factors, such as history of injecting drug use or blood transfusion. Furthermore, since the single affected individual by $\mathrm{HCV}$ infection was 68 -yearsold, there is a high chance of the HCV infection occurred prior to HIV infection. The limited number of individuals with $\mathrm{HCV}$ infection prevented us to draw more conclusions ans it is due to the main limitation of this study, its reduced sample size. This may result in a misrepresentation of the real HCV seroprevalence in the city of Belém.

Although we are aware of these limitations, our results may indicate the rise of a new scenario regarding the HIV/HCV co-infection prevalence in Belém, showing an important reduction of co-infection. It can also work as an important tool to further investigate the incidence of $\mathrm{HCV}$ infection in this specific population.

In conclusion, the seroprevalence of $\mathrm{HIV} / \mathrm{HCV}$ co-infection in the city of Belém was very low when compared to other Brazilian regions, but it is necessary to monitor these individuals in order to establish if the HIV infection can be a predisposing factor for HCV infection, since the population studied here only included newly-diagnosed HIV/AIDS patients.

\section{Funding}

This study was funded by Coordenação de Aperfeiçoamento de Pessoal de Nível Superior (CAPES), Ministry of education Brazil- Grant code 001. The publication of this article was supported by Public Notice PAPQ, PROPESP/FADESP of the Federal University of Pará.

\section{Ethical approval}

The study was approved by the ethics committee from the Instituto de Ciências da Saúde, Universidade Federal do Pará, under number 83450318.7.0000.0018.

\section{References}

Andreoni M, Giacometti A, Maida I, Meraviglia P, Ripamonti D, Sarmati L. 
2012. HIV-HCV co-infection: epidemiology, pathogenesis and therapeutic implications. European Review for Medical and Pharmacological Sciences. 16(11): 1473-83.

Brasil. Ministério da Saúde. 2002. Secretária de políticas de saúde. Coordenação Nacional de DST e Aids. Programa Nacional de Hepatites Virais. Recomendações para Tratamento da Co-Infecção entre HIV e Hepatites Virais. Ministério da Saúde. Brasília: Ministério da Saúde.

Low AJ, Mburu G, Welton NJ, May MT, Davies CF, French C, et al., 2016. Impact of Opioid Substitution Therapy on Antiretroviral Therapy Outcomes: A Systematic Review and Meta-Analysis. Clin Infect Dis. 63(8): 1094-1104.

Monteiro MR, do Nascimento MM, Passos AD, Figueiredo JF. 2004. Hepatitis C: prevalence and risk factors among patients with HIV/AIDS in Belém Pará, in Brazilian Amazon. Rev Soc Bras Med Trop. 37 Suppl 2: 40-6.

Pereira LMMB, Martelli CMT, Moreira, RC, Merchan-Hamman E, Stein AT, Cardoso MRA, et al., 2013. Prevalence and risk factors of hepatitis $\mathrm{C}$ virus infection in Brazil, 2005 through 2009: A cross-sectional study. BMC Infect. Dis. 13: 60.

Tizzot MR, Grisbach C, Beltrame MH, Messias-Reason IJ. 2016. Seroprevalence of HCV markers among HIV infected patients from Curitiba and metropolitan region. Rev Assoc Med Bras (1992). 62(1): 65-71.

Victoria MB, Victoria FS, Torres KL, Kashima S, Covas D, Malheiro A. 2010. Epidemiology of HIV/HCV coinfection in patients cared for at the Tropical Medicine Foundation of Amazonas. Brazilian Journal of Infectious Diseases. 14(2): 135-140.

\section{How to cite this article:}

Márcio Nahum Lobo, Jessica Leticia Santos Barata, Ronald Ferreira de Jesus, Julimar Benedita Gomes de Oliveira, Pedro Leão Fontes Neto, Andre Luis Ribeiro Ribeiro and Luiz Fernando Almeida Machado. 2018. Prevalence of HCV Infection in Newly-Diagnosed HIV Patients in the City of Belém, Pará, Brazil: A Preliminary Report. Int.J.Curr.Microbiol.App.Sci. 7(12): 3266-3270. doi: https://doi.org/10.20546/ijcmas.2018.712.377 